\title{
Status of astronomy Outreach in Chile
}

\author{
Estado del Alcance de la Astronomía en Chile
}

\author{
Farid Char ${ }^{1^{*}}$ \\ ${ }^{1}$ Universidad de Antofagasta, Chile \\ Correspondence \\ 1 Universidad de Antofagasta, Chile. \\ Email: farid.char@uantof.cl
}

Copyright : Licencia de Creative Commons Reconocimiento-NoComercial 4.0 Interna.

\section{@creative

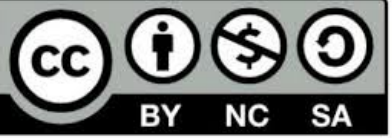

The publication of this journal is funded by Universidad ECCI, Bogotá-Colombia.

Editors: Adriana Suárez, Robert Paul Salazar

Editorial assistant : Luz Adriana Suáres Suáres.

\begin{abstract}
Currently, astronomy outreach in Chile is in good health. There is at least a dozen research groups belonging to universities, and most of them also include a specific area for Education and Public Outreach (EPO), using resources to communicate astronomy to the public. Amateur astronomy, astrotourism and astronomy clubs at schools are also important actors in astronomy outreach, as well as recent initiatives from the government recognizing the dark skies as our natural heritage, and promoting science as a useful tool for knowledge and development. This presentation summarizes some of these initiatives, focusing on creating new educative materials establishing alliances, and finally discussing how these efforts could consolidate the leadership of Chile in astronomy education, and how we could create new opportunities in South America on this topic.
\end{abstract}

keywords: astronomy, astrotourism.

\section{1 | RESUMEN}

Actualmente, el alcance de la astronomía en Chile goza de buena salud. Hay al menos una decena de grupos de investigación pertenecientes a universidades, y la mayoría de ellos también incluyen un área específica de Educación y Difusión Pública (EPO), utilizando recursos para comunicar la astronomía al público. Los clubes de aficionados de astronomía, astroturismo y astronomía en las escuelas también son actores importantes en el alcance de la astronomía, así como iniciativas recientes del gobierno reconociendo los cielos oscuros como nuestro patrimonio natural y promoviendo la ciencia como una herramienta útil para el conocimiento y el desarrollo. Esta presentación resume algunas de estas iniciativas, enfocándose en la creación de nuevos materiales educativos estableciendo alianzas y finalmente discutiendo cómo estos esfuerzos podrían consolidar el

*Equally contributing authors. 
liderazgo de Chile en la educación astronómica y cómo podríamos crear nuevas oportunidades en Sudamérica en este tema.

Palabras clave: astronomía, astroturismo.

\section{2 | INTRODUCTION}

The impact of astronomy in Chile is not only about having very good places to study our Universe, from the dark skies of the Atacama Desert. The Chilean astronomy community comprises the professional segment (about a dozen of institutions and academic groups, mainly from universities) and the amateur segment (including amateur astronomy groups, astronomy clubs at schools and other programs about astronomy outreach through astrotourism); these segments are very active and more developed than a decade

ago, but there is a lot of work to be completed yet. The government and related institutions are including astronomy among the key topics in the national plan to develop science and education, and the Regional Strategies of Innovation for those regions when astronomy is especially strong (north of Chile), while astrotourism is emerging as a new industry, with many efforts across the country whose main objective is communicate astronomy through the interactive exploration of the night skies. All of these projects can be considered part of the astronomy outreach in Chile, and there is a big challenge for the next decade: approximately $70 \%$ of all astronomical facilities in the world will be located in Chile, and this should be a great inspiration not only for the Chilean people, but also all South America, and the mission for the next generation of communicators must be identify what elements can inspire and motivate about astronomy, and how these elements can be helpful to develop our nation, but also other nations with a common identity and vision, such as the Andean countries.

\section{3 | PROFESSIONALS AND AMATEURS}

The Sociedad Chilena de Astronomía (SOCHIAS) coordinates the professional astronomy community in Chile, participating and/or funding some educational programs and projects (e.g. Chilean Astronomy Olympiads, Light Pollution, Astrotourism, Andean ROAD, etc.) and communicating outreach activities through its web page. This institution has a regular meeting every year to share and discuss the last advancements in many astronomy fields, but is also interested in promote science through different ways. Several groups compose the professional segment across the country, mostly composed by Chilean astronomers, but also foreign scientists. The main professional groups operating in Chile are the following:

- Departamento de Astronomía, Pontificia Universidad Católica de Chile

- Departamento de Astronomía, Universidad de Chile

- Unidad de Astronomía, Universidad de Antofagasta

- Instituto de Astronomía, Universidad Católica del Norte

- Departamento de Física y Astronomía, Universidad de La Serena

- Departamento de Astronomía, Universidad de Concepción

- Departamento de Astronomía, Universidad de Valparaíso

- Departamento de Ciencias Físicas, Universidad Andrés Bello

Although not these groups also includes an academic program of astronomy (at undergraduate and graduate levels), some of them are strongly involved in astronomy education, performing annual cycles of different activities, such as public talks, public observations, seasonal astronomy schools, open debates, workshop activities for teachers and students, and joint involvements on global programs, such as Globe at Night, Astronomy Day, International Observe the Moon Night, etc. The professional segment also includes to all professional observatories based in Chile, mostly operated by foreign consortiums, and they help to communicate astronomy 
through sponsorships, astronomy materials, talks from staff astronomers, etc.

Astronomy education is an important matter not only for the Chilean government (as will be mentioned later), but also for foreign institutions operating in Chile, such as these operating big observatories. A good example of this commitment was the First Chile-U.S. Astronomy Education Outreach Summit in Chile, organized by the U.S. observatories in Chile, The United States Embassy, CONICYT and Fundación Imagen de Chile during March 2015. This effort gathered several representatives from Chile and the U.S. in astronomy education, from many astronomy groups and Departments, in the aim to evaluate, discuss and propose new strategies for this matter, and develop a roadmap document based on findings from this event. Similar efforts have been implemented in Chile, with the important support from foreign consortiums, such as AstroDay Chile (supported by the GEMINI Observatory), the AwESOme Universe Exhibition (supported by the European Southern Observatory), the EduALMA project (joint collaboration between the Universidad de Antofagasta and the ALMA Observatory), and many others.

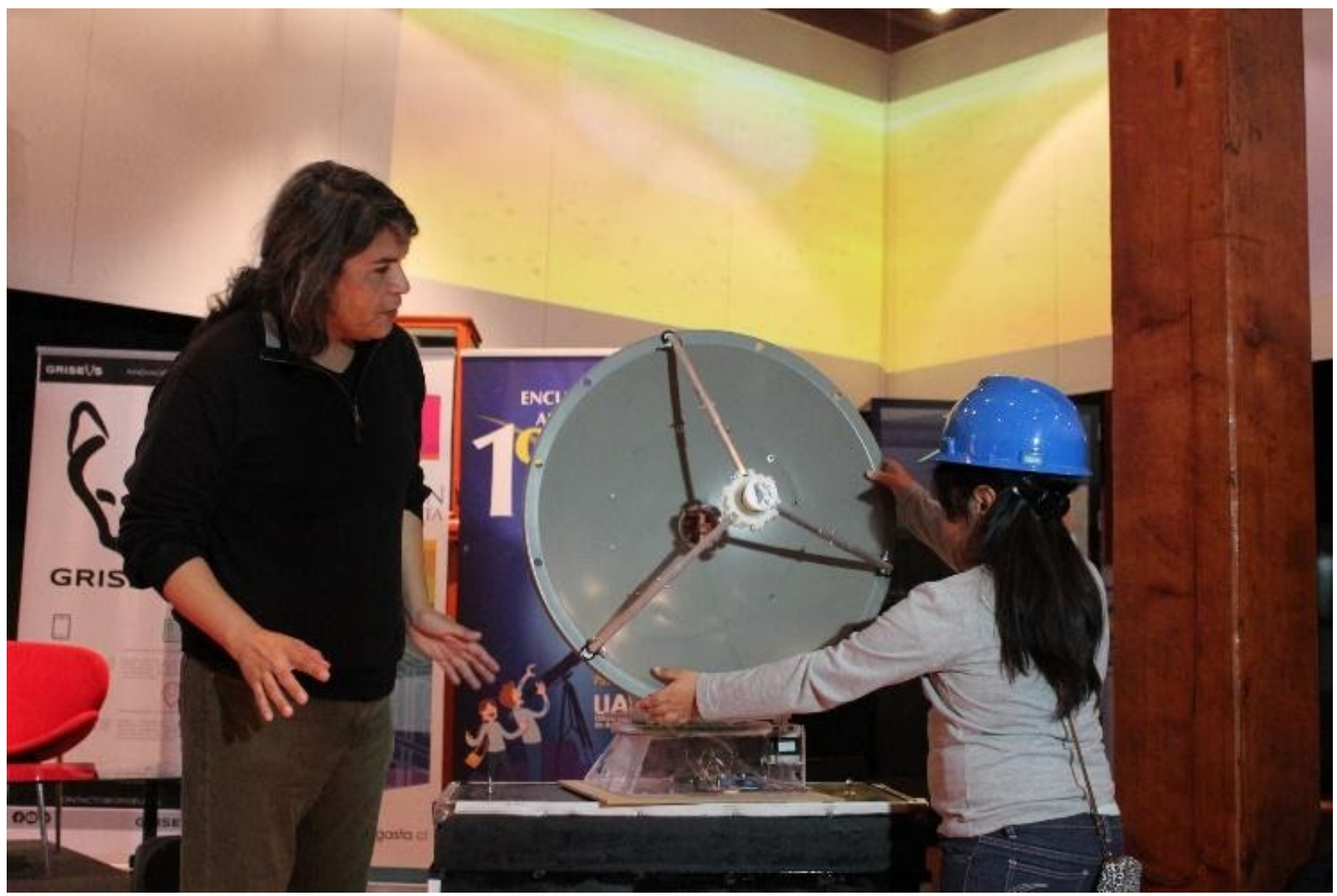

FIG. 1 Teaching radioastronomy to primary school students The main goal of EduALMA, a joint project between the Universidad de Antofagasta and the ALMA Observatory, was the creation of functional scale-models of "antennas" used for radioastronomy. Image courtesy of Eduardo Unda-Sanzana (UA)

Additionally, in the aim to communicate astronomy to the public in a real astronomical context, there are two Chilean-state owned observatories, whose activities are not only related to research, but also education: the Observatorio Astronómico Nacional (OAN) is located at Santiago and managed by the Universidad de Chile, with many astronomy courses offered to the general public through its Departamento de Astronomía; the Observatorio Ckoirama is located in the Atacama desert (close to Antofagasta city) and managed by the Universidad de Antofagasta, through its Unidad de Astronomía. Ckoirama [1] will receive general public and students, offering the possibility to observe the night skies from a professional observatory, providing a scientific and interactive experience, like no other professional observatory in Chile

The amateur astronomy community, in the other hand, has been involved in several activities and programs whose main goal is communicate astronomy at different levels [2][3]. This segment includes astronomy clubs 
at schools (managed by science teachers), the creation of amateur observatories for general public (managed by local entrepreneurs and tourism agencies), regular meetings and congresses (organized by different amateur groups across Chile), participation in Science Fairs and Astronomy Olympiads for high-school.

Students, etc. Although amateur activities are mostly focused on recreational experiences, such as stargazing sessions, astrophotography, astronomy camps, etc., a common objective for this community should be the establishment of a closer alliance with local universities and professional institutions, in the aim to develop fruitful astronomy activities and encourage amateurs to make real scientific contributions, and/or participate in global programs where human intervention is needed (e.g. Galaxy Zoo) and distributed computing projects, such as SETI@home, Asteroids@home, etc., involving citizen science as part of the learning process [4].

\section{1 | Astrotourism}

astrotourism. Taking advantage of its clear skies in the north region, several amateur observatories have been placed and operated by local entrepreneurs, tourism agencies and the government. Most of these projects are located near La Serena city, close to professional observatories (such as Tololo, La Silla, Gemini, etc.) while new projects are located near Antofagasta and San Pedro de Atacama, close to other professional facilities, such as ALMA and Paranal. Some of the active amateur observatories in this category are the following:

- Observatorio comunal Cerro Mamalluca

- Observatorio astronómico Cruz del Sur

- Observatorio astronómico del Pangue

- Observatorio astronómico Collowara

- Observatorio astronómico Cerro Mayu

- Observatorio astronómico Paniri Caur

- Observatorio Astronómico Andino

- Observatorio astronómico Inca de Oro

Currently, not only many amateur observatories are offered to the public in the north of Chile, but also 'astronomical lodging' and different options to enjoy the night skies, focused on national and international visitors, students and amateur astronomers. Many actors are involved in this new offer (including professional observatories allowing visitors), and those resources unfold new opportunities but also new communicators (astronomy tourist guides), and understanding this way of astronomy outreach is critical if Chile wants to be a recognized place for enjoy astronomy without being an astronomer. During 2015, the project 'Astroturismo Chile' has been in charge to study the current astrotourism offer across Chile, delivering a diagnostic about this activity and creating a large database of the current actors involved.

A good example of how astrotourism has become an important way to communicate astronomy is the growing amount of amateur observatories across Chile, according to Astroturismo Chile, and the increasing number of visitors to such facilities. Since professional observatories (Paranal, Tololo, La Silla and ALMA) also can be visited (only during daytime), these should be included as an excellent relationship between professional and amateur efforts to communicate different perspectives of astronomy. Additional resources are mobile and digital planetariums, and the Planetario of the Universidad de Santiago de Chile is the most remarkable facility for virtual shows of the night sky, and a couple of two interactive initiatives can also be added, such as the Museo Interactivo Mirador at Santiago and CICAT (Centro Interactivo de Ciencias, Artes y Tecnologías) at Concepción, mostly involved in teaching about general science, physics, nature, biology, robotics and more.

\section{4 | GOVERNMENT AND NEW PARTNERS}

The Chilean Government, through the Comisión Nacional de Investigación, Ciencia y Tecnología (CONICYT) and the Explora Associative Regional Program across the country, among other sources, offer many ways and annual funding opportunities to develop astronomy in Chile, focused on astronomy/science outreach. Some 
of these efforts are the following:

- Science Camps 'Chile VA' from the Program Explora CONICYT.

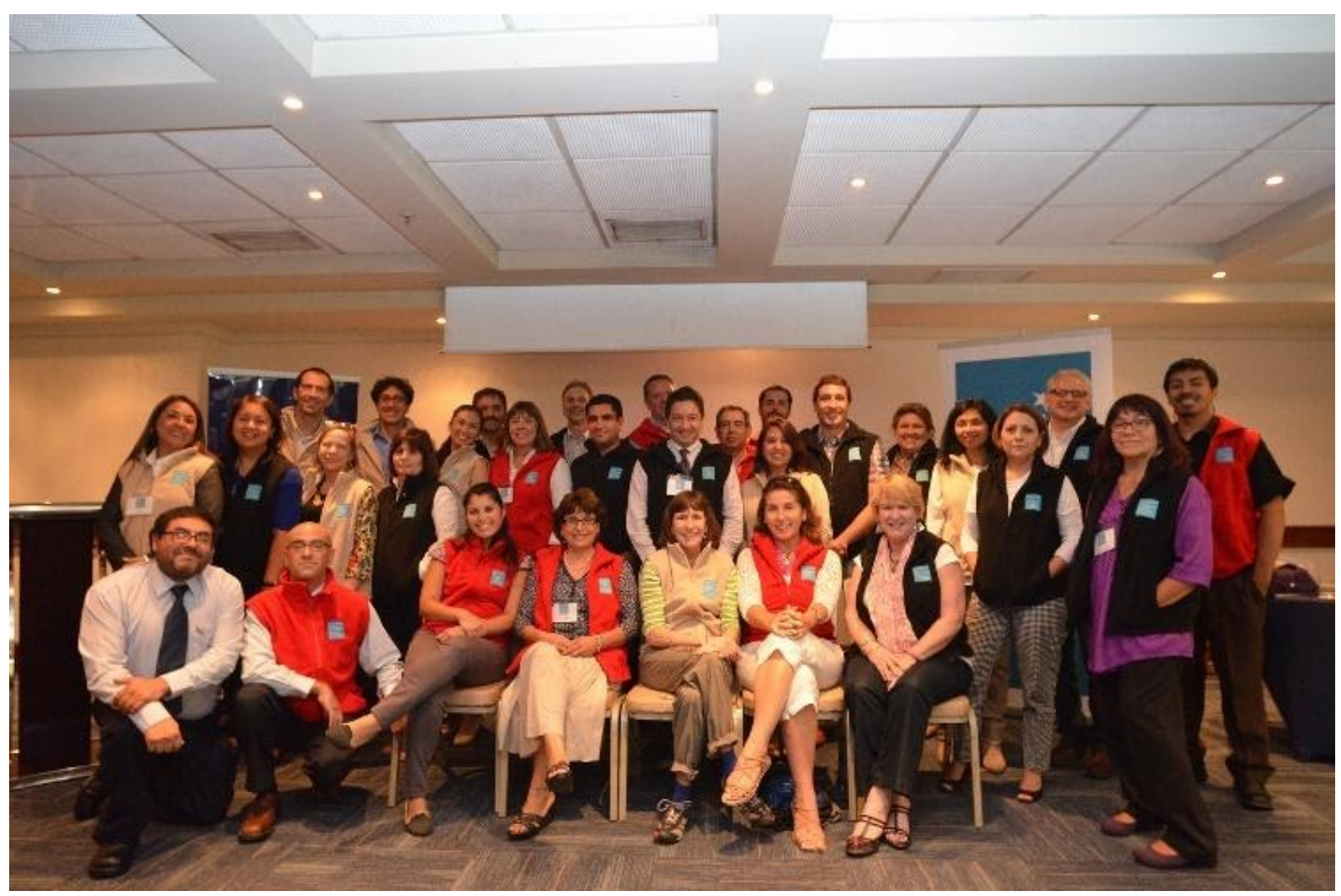

FIG. 2 st Chile-U.S. Astronomy Education Outreach Summit in Chile. The participants of this Summit discussed successful models in formal and informal education, community engagement, and astro-tourism, and will also take advantage of opportunities for networking and partnerships among Chilean and U.S. institutions.

Image courtesy of Daniel Munizaga (CTIO)

- Fondo de Innovación para la Competitividad Regional FIC-R

- Fondo FNDR 2

- ESO-Chile Joint Committee funds

- ALMA-CONICYT funds for the development of Chilean astronomy

- GEMINI-CONICYT funds for the development of astronomy and related sciences

- QUIMAL astronomy funds for the development of technologies of national astronomy.

The commitment from the Chilean government about astronomy can be seen during the 2015 XXIX General Assembly of the International Astronomical Union (IAU) at Honolulu (Hawaii, United States), through a bid to propose Chile as the host country for the XXXI IAU GA in 2021. The IAU GA is the most important professional astronomy meeting, gathering more than one thousand astronomers from the many countries in the world, held every three years. Although the Chilean bid was not successful (the 2021 IAU GA will be held in South Korea), this is a good sign to keep working and take new challenges, in order to consolidate the role of Chile as worldwide leaders in astronomy.

There is another important message coming from these national efforts: Chilean astronomy cannot be only 
about provide services to foreign institutions which wants to emplace big observatories in our territory; now is also about the active participation in such projects, helping to develop technologies (through astro-engineering projects hosted by

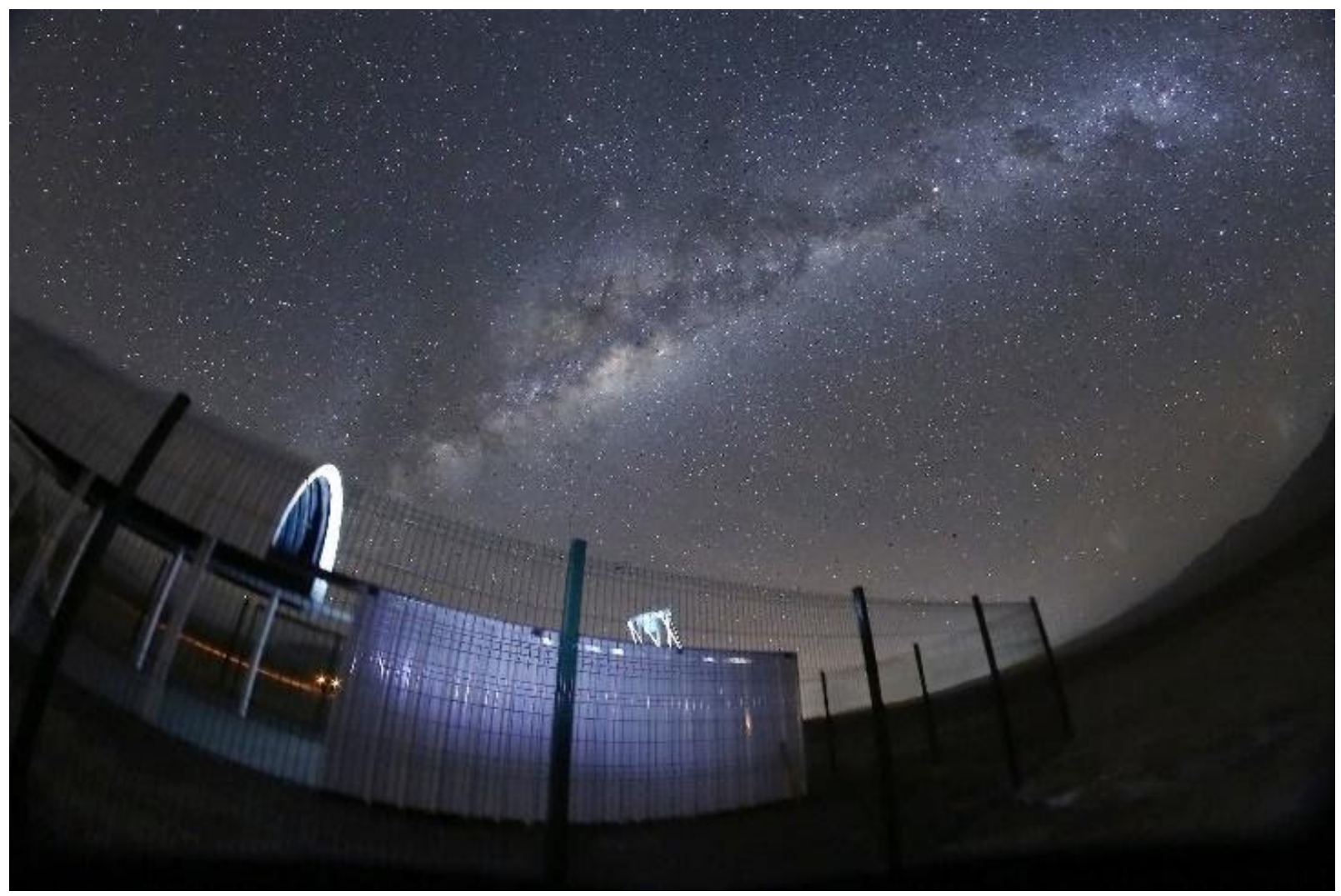

FIG. 3 Ckoirama under the Milky Way The first Chilean-state owned observatory under desert skies, will use a $0.6-\mathrm{m}$ telescope as the main instrument, and a secondary $0.35-\mathrm{m}$ telescope, only for astrotourism and education.

Image courtesy of Farid Char (UA)

some universities, such as the Pontificia Universidad Católica, Universidad de Chile and Universidad de Antofagasta), or investing money in professional observatories. As noted before, Chile has two Chilean-state owned observatories, but only the Ckoirama Observatory, operated by the Unidad de Astronomía of the Universidad de Antofagasta, is located under desert skies at the Atacama Desert. Ckoirama will produce scientific contributions through its main $0.6-\mathrm{m}$ telescope, while a secondary $0.35-\mathrm{m}$ telescope will be available only for astrotourism and education, providing an interactive astronomy experience in a professional context, under top-class quality skies.

Astronomy is also about partnerships, and Chile is looking for new collaborations and partners not only about research, but also about outreach. This is why our country joined the recent Andean Regional Office of Astronomy for Development (Andean ROAD), an international effort composed by six countries (Bolivia, Colombia, Chile Ecuador, Perú and Venezuela), under supervision of the Office of Astronomy for Development (OAD) of the IAU. The main goal of the Andean ROAD is to guarantee and strengthen effective methods of communication between the representatives and coordinators of global, regional and local projects implemented in the Andean countries, through the three Task Forces established by the 2010-2010 Strategic Plan [5] of the OAD : (i) Astronomy for Universities and Research, (ii) Astronomy for Children and Schools and (iii) Astronomy for the Public. The signing institutions of the Andean ROAD (Executive Board) are composed by the Universidad de los Andes and Parque Explora (Colombia) and Sociedad Chilena de Astronomía (Chile). Regarding the Chilean division, and additional National Coordination Office has been created, in order to stay 
in communication with the Andean ROAD, coordinating new activities and projects on behalf of this international alliance. We expect to develop fruitful partnerships with Andean institutions in the near future, sharing experiences and looking for new opportunities in outreach astronomy within South America, since the Andean countries represent not only a common block of Spanish-speaking countries, but also a vision about astronomy and culture.

\subsection{Conclusions}

The total income of the IAU is less than $€ 1$ million; however, the IAU has committed to increase expenditure on educational activities during the next triennium from $10 \%$ to $17 \%$ of its total budget, with $€ 140.000$ per year . This is just an example of how educational activities and astronomy outreach has become a relevant matter, and a global concern about how astronomy can contribute to development in the world. Chile is one of the top places on Earth for professional astronomy, and the only one in South America able to hold many professional facilities. This advantage is already exploited by foreign -and national- efforts for academic research, but it is time to exploit our natural heritage to teach astronomy and share experiences not only with the "general public" and "general students", but also the future new generation of astronomers and scientists.

South America has many natural resources and qualified people to exploit these resources, but a common lack of the South American countries -even Chile- is the ability to develop new unpublished educational materials for teaching science, and astronomy is not the exception. The current global programs about astronomy education, such as UNAWE, Galileo Teachers Training Program, Hands-On Universe and many others, are coming from North America and/or Europe, but this is the time to take the challenge and develop new materials and experiences according to our reality and our -mostly southern- skies. A great example is the Galileo

Mobile project, founded by a Colombian astronomer and composed by an international team of enthusiast astronomy communicators, visiting many countries around, especially in South America; the NASE Program (Network for Astronomy School Education) from the IAU, with lots of experiences in Central and South America, with local contacts and spin-off projects in dozens of countries (coming soon with the first NASE courses in Chile, 2016).

Chile has the great opportunity to take the leadership in astronomy outreach, but the main goal must be ability to work close to other countries, as real partners, developing new strategies to turn astronomy as a tool for development. Specific meetings, such as the Communicating Astronomy with the Public Conference (16-20 May 2016 in Medellín, Colombia) or the XV Latin American Regional IAU Meeting (3-7 October 2016 in Cartagena de Indias, Colombia), should be a great opportunity to work together and improve our astronomy outreach status, but also learning from others and help preparing the new generation of astronomers and scientists, to a new era of astronomical discoveries.

\section{5 | ACKNOWLEDGEMENTS}

The author would like to acknowledge the many valuable suggestions and information provided by the following people and institutions:

- Dr. Jaime Forero-Romero, Universidad de los Andes, Colombia.

- Dr. Eduardo Unda-Sanzana, Universidad de Antofagasta, Chile.

- Ángela Pérez Henao, Parque Explora in Medellín, Colombia.

- Dr. Patricio Rojo, Universidad de Chile and Observatorio Astronómico Nacional, Chile.

- Kevindran Govender, Office of Astronomy for Development, Cape Town, South Africa.

- Rosa M. Ros and Beatriz García, NASE Program, IAU.

- Aída del Pilar Becerra, Galileo Mobile Program.

- Verde Consulting Group, Santiago, Chile. 


\section{References}

[1] F. Char, E. Unda-Sanzana, J. Colque, S. Fossey, and M. Rocchetto, "Ckoirama, the first chilean-state owned observatory under desert skies," BAAA, vol. 58, pp. 200-202, 2016.

[2] V. Consulting, "Group, levantamiento de información sobre aficionados a la astronomía. informe final," 2015.

[3] L. A. Núñez and H. Rago, "Astronomía al aire: Mass media convergence in astronomy and astrophysics," Tecciencia, vol. 11, no. 21, pp. 13-16, 2016. DOl: http://dx.doi.org10.18180/tecciencia.2016.21.3

[4] K. D. Borne, S. Jacoby, K. Carney, A. Connolly, T. Eastman, M. J. Raddick, J. Tyson, and J. Wallin, "The revolution in astronomy education: data science for the masses," arXiv preprint arXiv:0909.3895, 2009.

[5] I. A. Union, "Astronomy for development strategic plan 2010-2010,"

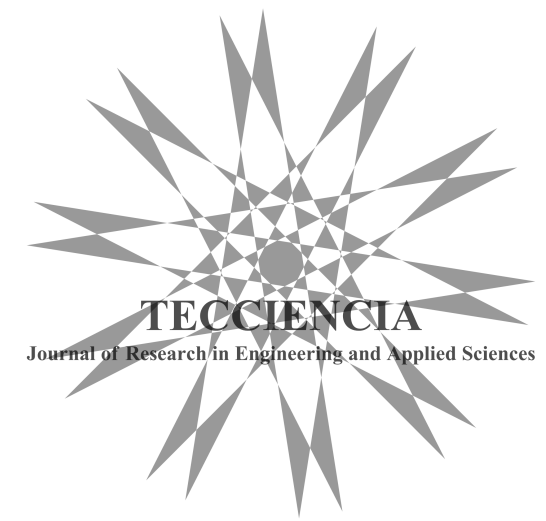

